\title{
Tribological Testing of Some Potential PVD and CVD Coatings for Steel Wire Drawing Dies
}

\author{
M. Nilsson* and M. Olsson \\ Dalarna University, SE-781 88 Borlänge, Sweden \\ *mnn@du.se
}

\begin{abstract}
The aim of this study was to investigate the possibility to replace cemented carbide wire drawing dies with CVD or PVD coated steel dies. Material pick-up tendency, friction and wear characteristics of four different coatings - CVD TiC and PVD (Ti,Al)N, CrN and CrC/C - in sliding contact with ASTM 52100 bearing steel were evaluated using pin-on-disc testing. The load bearing capacity of the coating/substrate composites was evaluated using scratch testing. Based on the results obtained in this study, three different coatings $-\mathrm{CrC} / \mathrm{C}$, $\mathrm{TiC}$ and dual-layer $\mathrm{TiC} / \mathrm{CrC} / \mathrm{C}-$ are recommended to be evaluated in wire drawing field tests.
\end{abstract}

Key words: Drawing die, coating, wear

\section{INTRODUCTION}

Wire drawing is a cold work production process in which wires of desired diameters with low tolerances and smooth surfaces for various applications are produced by pulling the wire through one or a series of reducing dies. Cemented carbide, showing a combination of high hardness, sufficient toughness and excellent wear resistance, is today the most frequently used drawing die material in steel wire drawing applications. However, the increasing cost of cemented carbide in combination with the possibility to increase the wear resistance of steel through the deposition of wear resistant CVD and PVD coatings have increased the interest for steel wire drawing dies during the last years.
During the reduction in the drawing die, the die surface is exposed to high compressive and shear stresses resulting in wear. In general three different wear zones can be distinguished [1]. The first wear zone is close to the entry plane where the wire first gets in contact with the die. The second wear zone is the drawing cone and the third is the bearing at the die exit. Consequently, lubrication is of outmost importance in order to reduce the friction and die wear during wire drawing and today soap powder is frequently used for this purpose. When the wire rod enters the die, it will carry soap powder particles into the wedge between the wire and the die and consequently the surface roughness of the wire plays an important role in the lubrication of the contacting surfaces.

The dominating wear mechanisms of drawing dies used for steel wire drawing are adhesive and abrasive wear. Surface fatigue may possibly also 
take place due to cyclic repeated contacts and cyclic load fluctuations. Adhesive wear may occur if wire material sticks to the die surface and every now and then small fragments are separated from the die by adhesive shear and fracture. Abrasive wear may occur if hard oxide fragments or inclusions in the surface of the wire scratch the surface of the drawing die [2].

In order to reduce the friction forces and the mechanical interaction between the drawing die and the wire rod, the harder die material surface topography must be kept at a low level. Thus, polishing of the die surface removing surface asperities and irregularities will improve the surface quality of the wire rod but also the performance and wear resistance of the drawing die. A rule of thumb is that a surface roughness of $\mathrm{R}_{\mathrm{a}}=0.05 \mu \mathrm{m}$ or better will significantly improve the performance of the drawing die [3].

Miller [4], Miura et al. [5], Murakawa et al. [6], Van Halewijn [7] and Sun et al. [8] have all investigated the performance of CVD diamond coated cemented carbide dies. Otherwise, data concerning the tribological performance of various types of CVD and PVD coatings used in wire drawing applications are relatively rare in the open literature. Nevertheless, during the last years PVD and CVD coatings have been increasingly used in metalworking applications, such as rolling and extrusion. The advantage of these coating deposition techniques is that less wear resistant materials can be used as substrates and coated by wear resistant coatings in order to get the desired surface materials' properties.

The objective of the present study was to evaluate the possibility to use a high-strength throughhardening bearing steel as a substrate for CVD and PVD coatings and to evaluate the friction and sliding wear characteristics of the coatings in contact with ASTM 52100 bearing steel.

\section{EXPERIMENTAL}

\subsection{Materials}

Circular discs (thickness $5 \mathrm{~mm}$, diameter $50 \mathrm{~mm}$ ) made from Ovatec 677, a high-strength throughhardening bearing steel (chemical composition: $0.67 \% \mathrm{C}, 1.50 \% \mathrm{Si}, 1.50 \% \mathrm{Mn}, 1.00 \% \mathrm{Cr}, 0.10$ $\% \mathrm{Ni}, 0.25 \% \mathrm{Mo}$, bal. Fe), were used as substrate material in the present study. Prior to the coating deposition all substrates were grinded and polished using $3 \mu \mathrm{m}$ diamond in the last step.

Four different coatings - CVD TiC and PVD (Ti,Al)N, CrN and $\mathrm{CrC} / \mathrm{C}$ - were deposited on the substrates by IonBond Sweden. The coating thickness, hardness and deposition temperature are presented in Table 1.

Due to the low tempering temperature of Ovatec 677 , only the $\mathrm{CrC} / \mathrm{C}$ coating was deposited on heat treated substrates. On the contrary, the $\mathrm{TiC}, \mathrm{CrN}$ and (Ti,Al)N coatings were deposited on annealed substrates which were post-heat treated by hardening at $960^{\circ} \mathrm{C}$ for 35 minutes followed by cooling in helium and tempering at $200^{\circ} \mathrm{C}$ for 120 minutes. This heat treatment resulted in a substrate hardness of $745 \mathrm{HV}_{0.05}$. Both hardening and tempering were made in vacuum chambers. The uncoated and coated samples were then either tested in the as-heat treated/as-deposited condition or polished using $3 \mu \mathrm{m}$ diamond and tested in the post-polished condition. In the following sections these conditions will be referred to as the asdeposited condition and the post-polished condition.

In all experiments ASTM 52100 bearing steel (chemical composition: 0.95-1.00\%C, 0.20-0.35 $\% \mathrm{Si}, 0.20-0.40 \% \mathrm{Mn}, 1.35-1.60 \% \mathrm{Cr}, 0.25 \% \mathrm{Ni}$, $0.08 \%$ Mo, bal. Fe, hardness $210 \mathrm{HV}_{1.0}$ ) was used as the counter material. 
Table 1. Characteristics of the coatings investigated

\begin{tabular}{|c|c|c|c|}
\hline $\begin{array}{c}\text { Coating } \\
\text { material }\end{array}$ & $\begin{array}{c}\text { Hardness* } \\
{\left[\mathrm{HV}_{0.05}\right]}\end{array}$ & $\begin{array}{c}\text { Thickness* } \\
{[\mu \mathrm{m}]}\end{array}$ & $\begin{array}{c}\text { Deposition } \\
\text { temperature }\end{array}$ \\
\hline $\mathrm{TiC}$ & 4500 & $6-8$ & $950-1050^{\circ} \mathrm{C}$ \\
\hline $\mathrm{CrC} / \mathrm{C}$ & 1500 & $1.5-2$ & $180^{\circ} \mathrm{C}$ \\
\hline $\mathrm{CrN}$ & 2200 & $3-4$ & $\sim 200^{\circ} \mathrm{C}$ \\
\hline$(\mathrm{Ti}, \mathrm{Al}) \mathrm{N}$ & 3300 & $3-5$ & $\sim 450^{\circ} \mathrm{C}$ \\
\hline
\end{tabular}

* Nominal values given by IonBond

\subsection{Experimental work}

The mechanical response (load bearing capacity of the coating/substrate composites) during scratching was evaluated using a conventional scratch tester, CSM Revetest ${ }^{\circledR}$, equipped with a Rockwell-C diamond stylus with a radius of 200 $\mu \mathrm{m}$ and $500 \mu \mathrm{m}$, respectively. A scratching length of $20 \mathrm{~mm}$, a loading rate of $100 \mathrm{~N} / \mathrm{min}$ and a normal load range of $10-100 \mathrm{~N}$, were used in the experiments. The critical normal load $\left(F_{\mathrm{N}, \mathrm{C}}\right)$ was used as a measure of the coating cohesion/adhesion and it was taken as the normal load corresponding to the first coating failure as detected by scanning electron microscopy (SEM). The scratch experiments were performed on the as-deposited samples.

3D surface topography measurements of the substrate surfaces and the coated substrates, both in the as-deposited and post-polished condition, were performed using a 3D optical topometer (Wyko NT9100).

The tribological characteristics were evaluated using pin-on-disc testing in combination with posttest observations of the tribo surfaces using scanning electron microscopy (SEM) and energy dispersive X-ray spectroscopy (EDX). The pin-ondisc tests were performed using a commercial CSM Tribometer with the test configuration schematically illustrated in Fig. 1. In the test, the pin made of ASTM 52100 with a diameter of 10 $\mathrm{mm}$ and a grinded, hemispherical shaped end surface (radius $5 \mathrm{~mm}$ ) was loaded against a rotating disc made of Ovatec 677. The discs were tested in both uncoated and coated conditions.

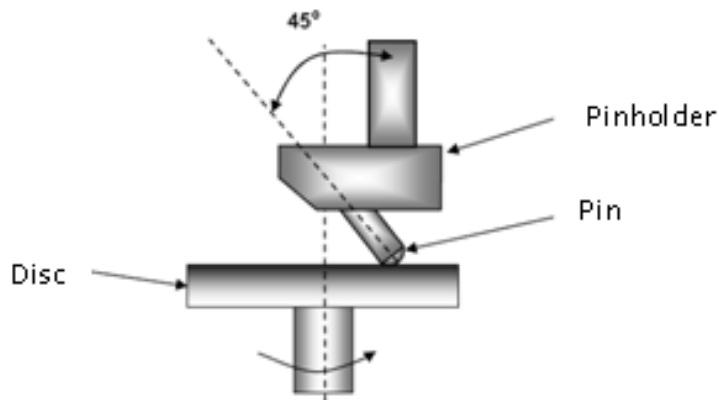

Figure 1. Schematic showing of the pin/disc contact.

The test parameters in this study were chosen in order to simulate the contact conditions, i.e. the process parameters used, in the wire drawing process. Wire drawing is a cold work production process, which means that the steel wire to be drawn is of room temperature, and therefore the pin-on-disc tests were run at ambient air conditions $\left(21-22{ }^{\circ} \mathrm{C}, 25-26 \% \mathrm{RH}\right)$. The tests were performed using a normal load of $5 \mathrm{~N}$, which corresponds to a maximum and mean Herzian contact pressure of $800 \mathrm{MPa}$ and $540 \mathrm{MPa}$, respectively, i.e. close to the mean contact pressure $650 \mathrm{MPa}$ in the wire drawing process investigated. In the tests, a relative sliding speed of $0.5 \mathrm{~m} / \mathrm{s}(30 \mathrm{~m} / \mathrm{min})$, a commonly used speed in wire drawing process, was used. The tests were run for a sliding distance of $200 \mathrm{~m}$ and during testing the friction coefficient was continuously recorded. For each material combination three tests were performed using different track radii, i.e. $10.0 \mathrm{~mm}, 13.0 \mathrm{~mm}$ and $16.0 \mathrm{~mm}$, respectively. Tests were performed under both dry and lubricated conditions, using a sodium stearate based soap powder, Traxit V $20 \mathrm{NW}$, as a lubricant.

\section{RESULTS}

Table 2 gives the critical normal loads of the coating composites investigated. All coatings displayed a cohesive type of failure, i.e. tensile cracking, conformal cracking or chipping, at the critical normal load. Coating failure was frequently accompanied by a significant increase in friction coefficient, see Fig 2. 
Figure 3 shows the results from the surface topography measurements of the $\mathrm{TiC}$ coated Ovatec 677 sample, where Fig. 3 a shows the TiC coating in the as-deposited condition while Fig. 3 $\mathrm{b}$ shows the $\mathrm{TiC}$ coating in the post-polished condition. The bearing curves seen in Fig. $3 \mathrm{c}$ show that the peaks of the as-deposited coating surface morphology are completely removed by the polishing, while a small fraction of the surface pits is still present. Table 3 gives the surface roughness of all samples investigated, both in the as-deposited and the post-polished condition. As can be seen, all coated samples show a higher surface roughness than the uncoated samples. The TiC coating displayed by far the roughest surface while the $\mathrm{CrC} / \mathrm{C}$ displayed the smoothest surface.

Figure 4 shows the friction characteristics for the steel pin in sliding contact with the as-deposited (Fig. 4a) and post-polished (Fig. 4b) TiC coating under both dry and lubricated sliding conditions. As can be seen, both the lubrication and the postpolishing of the as-deposited coating morphology significantly decrease the friction coefficient. The friction characteristics of the other coated samples displayed a similar appearance although the effect of lubrication and post-polishing was most pronounced for the TiC coating, see Table 4. As can be seen from the Table, the $\mathrm{CrC} / \mathrm{C}$ coated sample showed the overall lowest friction coefficient, $\mu$ in the range $0.15-0.30$, in all tests.

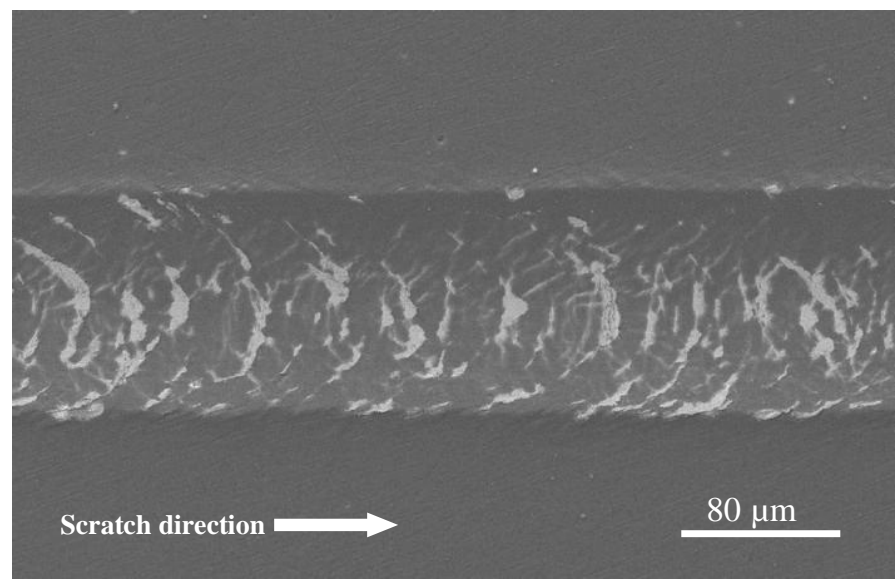

a)

Figure 2. a) SEM micrograph of the failure of the CrC/C coating at a load of $80 \mathrm{~N}$ when using a $200 \mu \mathrm{m}$ Rockwell-C diamond stylus. b) Friction coefficient versus load for the $\mathrm{CrC} / \mathrm{C}$ coated sample.
Figure 5 shows SEM micrographs of the asdeposited TiC coating after dry (Fig. 5a) and lubricated (Fig. 5b) sliding contact with the ASTM 52100 pin. A significant amount of pin material has been transferred to the coating surface both under dry and lubricated conditions, the former resulting in the largest amount of material pick-up and consequently the highest wear of the pin. On the contrary, the post-polished $\mathrm{TiC}$ coating shows virtually no material pick-up under either dry or lubricated conditions, see Fig. 5c. Inspection of the corresponding contact surfaces of the pins reveals the absence of wear, see Fig. 5d. A similar material pick-up tendency was observed for the other coated samples investigated. Table 4 shows the friction and wear characteristics of the sliding couples investigated in the pin-on-disc tests. The wear coefficient of the pin gives an indication of the tendency for a coated steel wire drawing die to scratch the wire rod during the drawing process.

Table 2. Critical normal load of the coating/substrate composites as obtained in the scratch test.

\begin{tabular}{|c|c|c|}
\hline \multirow{2}{*}{} & \multicolumn{2}{|c|}{ Critical normal load [N] } \\
\cline { 2 - 3 } & $\mathrm{r}=200 \mu \mathrm{m}^{*}$ & $\mathrm{r}=500 \mu \mathrm{m}^{*}$ \\
\hline $\mathrm{TiC}$ & 20 & 60 \\
\hline $\mathrm{CrC} / \mathrm{C}$ & 80 & $>100$ \\
\hline $\mathrm{CrN}$ & 75 & $>100$ \\
\hline$(\mathrm{Ti}, \mathrm{Al}) \mathrm{N}$ & 85 & $>100$ \\
\hline
\end{tabular}

*Radius of diamond stylus

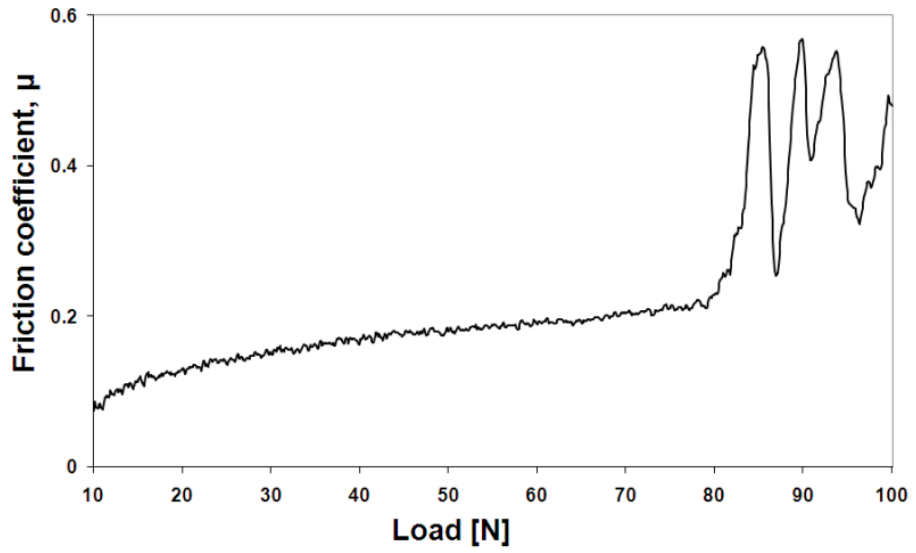

b) 


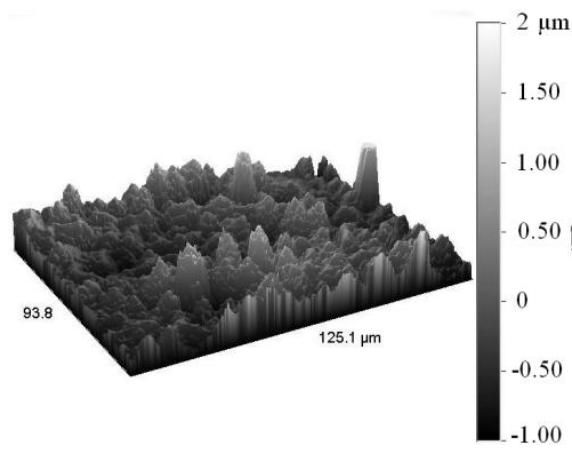

a)

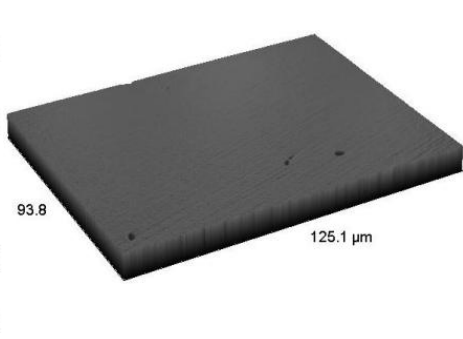

b)

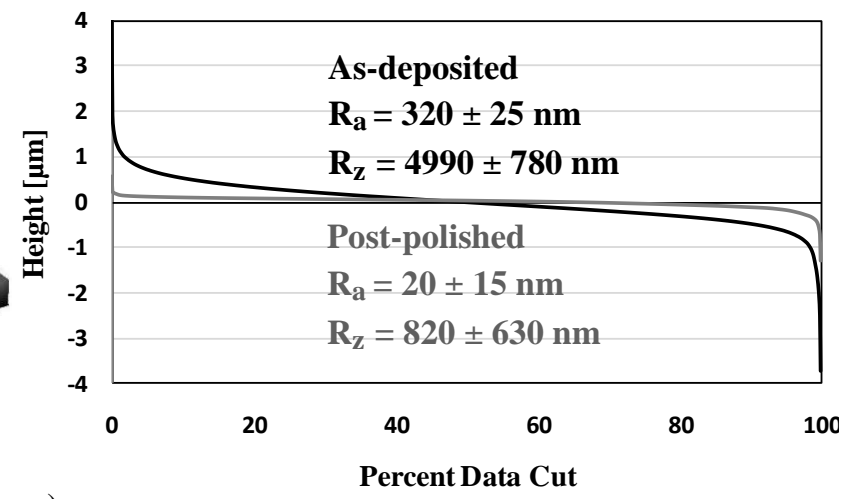

c)

Percent Data Cut

Figure 3. 3D-surface topography of TiC coating in the a) as-deposited and b) post-polished condition. c) Bearing curves of as-deposited (black) and post-polished (grey) TiC coating illustrating the effect of the polishing treatment.

Table 3. Surface roughness of the substrate and the four coatings in as-deposited as well as in post-polished condition.

\begin{tabular}{|c|c|c|c|c|}
\hline \multirow{2}{*}{} & \multicolumn{2}{|c|}{ As-deposited } & \multicolumn{2}{c|}{ Post-polished } \\
\cline { 2 - 5 } & $\mathrm{R}_{\mathrm{a}}[\mathrm{nm}]$ & $\mathrm{R}_{\mathrm{z}}[\mathrm{nm}]$ & $\mathrm{R}_{\mathrm{a}}[\mathrm{nm}]$ & $\mathrm{R}_{\mathrm{z}}[\mathrm{nm}]$ \\
\hline $\mathrm{Steel}$ & $95 \pm 5^{*}$ & $1490 \pm 60^{*}$ & $5 \pm 1$ & $100 \pm 50$ \\
\hline $\mathrm{TiC}$ & $320 \pm 25$ & $4990 \pm 780$ & $20 \pm 15$ & $820 \pm 630$ \\
\hline $\mathrm{CrC} / \mathrm{C}$ & $90 \pm 5$ & $2100 \pm 30$ & $60 \pm 15$ & $1330 \pm 670$ \\
\hline $\mathrm{CrN}$ & $145 \pm 5$ & $3830 \pm 90$ & $25 \pm 5$ & $1180 \pm 330$ \\
\hline$(\mathrm{Ti}, \mathrm{Al}) \mathrm{N}$ & $130 \pm 20$ & $3670 \pm 210$ & $75 \pm 30$ & $2820 \pm 1030$ \\
\hline
\end{tabular}

*Polished and post-heat treated
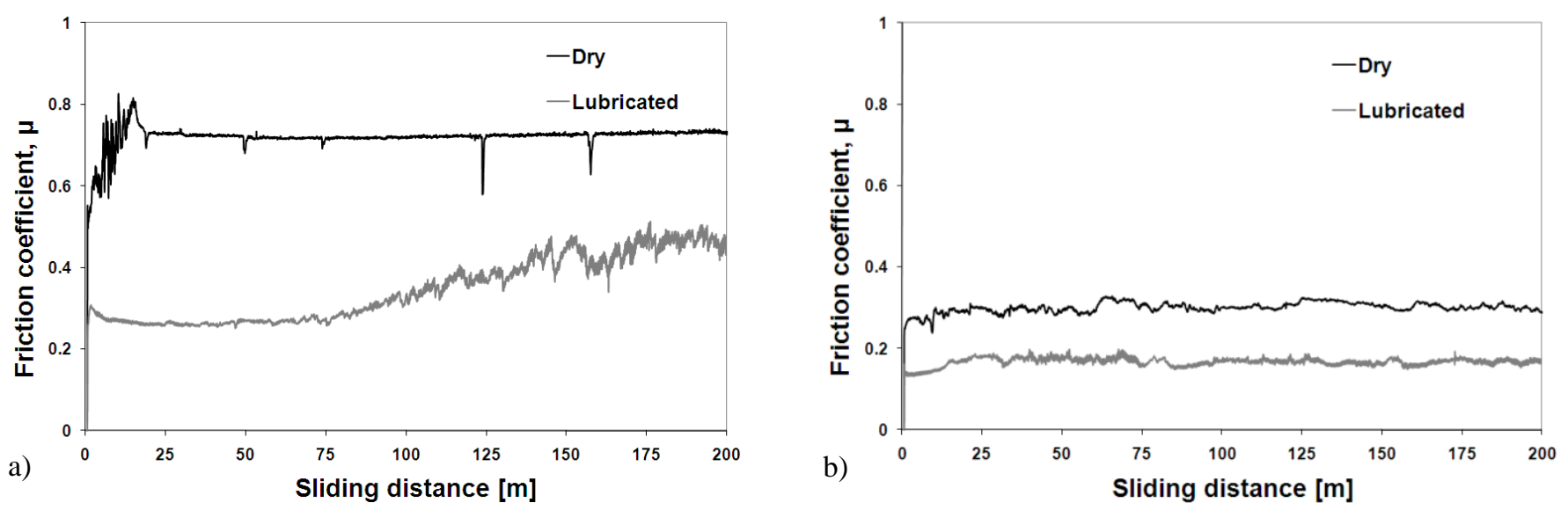

Figure 4. Friction characteristics of ASTM 52100 steel sliding against TiC coated steel under dry (black) and lubricated (grey) contact conditions. The graphs in a) correspond to an as-deposited coating topography while the graphs in b) correspond to a post-polished coating topography. 
Table 4. Friction and wear characteristics of the sliding couples investigated in the pin-on-disc tests.

\begin{tabular}{|c|c|c|c|c|c|c|c|}
\hline \multirow{2}{*}{} & \multicolumn{3}{|c|}{ As-deposited } & \multicolumn{3}{c|}{ Post-polished } \\
\cline { 3 - 8 } & \multicolumn{2}{|c|}{ Friction coefficient } & Wear coefficient* & \multicolumn{2}{|c|}{ Friction coefficient } & Wear coefficient* \\
\cline { 3 - 8 } & $\mu_{\text {initial }}$ & $\mu_{\text {steady-state }}$ & {$\left[10^{-6} \cdot \mathrm{mm}^{3} /(\mathrm{Nm})\right]$} & $\mu_{\text {initial }}$ & $\mu_{\text {steady-state }}$ & {$\left[10^{-6} \cdot \mathrm{mm}^{3} /(\mathrm{Nm})\right]$} \\
\hline \multirow{3}{*}{ Steel } & Dry & $0.5^{* *}$ & $0.8^{* *}$ & $42^{* *}$ & 0.4 & 0.9 & 56 \\
\cline { 2 - 8 } & Lubricated & $0.15^{* *}$ & $0.3^{* *}$ & $2.5^{* *}$ & 0.15 & 0.15 & Not measureable \\
\hline \multirow{2}{*}{$\mathrm{TiC}$} & Dry & 0.55 & 0.75 & 520 & 0.25 & 0.3 & 0.002 \\
\cline { 2 - 8 } & Lubricated & 0.3 & 0.35 & 180 & 0.15 & 0.15 & Not measureable \\
\hline \multirow{2}{*}{$\mathrm{CrC} / \mathrm{C}$} & Dry & 0.3 & 0.25 & 0.13 & 0.2 & 0.15 & Not measureable \\
\cline { 2 - 8 } & Lubricated & 0.15 & 0.2 & 0.051 & 0.15 & 0.15 & Not measureable \\
\hline \multirow{2}{*}{$\mathrm{CrN}$} & Dry & 0.6 & 0.75 & 50 & 0.6 & 0.65 & 22 \\
\cline { 2 - 8 } & Lubricated & 0.35 & 0.4 & 47 & 0.2 & 0.15 & Not measureable \\
\hline \multirow{2}{*}{$(\mathrm{Ti}, \mathrm{Al}) \mathrm{N}$} & Dry & 0.65 & 0.75 & 350 & 0.3 & 0.55 & 7.0 \\
\cline { 2 - 8 } & Lubricated & 0.3 & 0.35 & 100 & 0.15 & 0.15 & Not measureable \\
\hline
\end{tabular}

*Wear coefficient of the ASTM 52100 pin.

** Polished and post-heat treated.

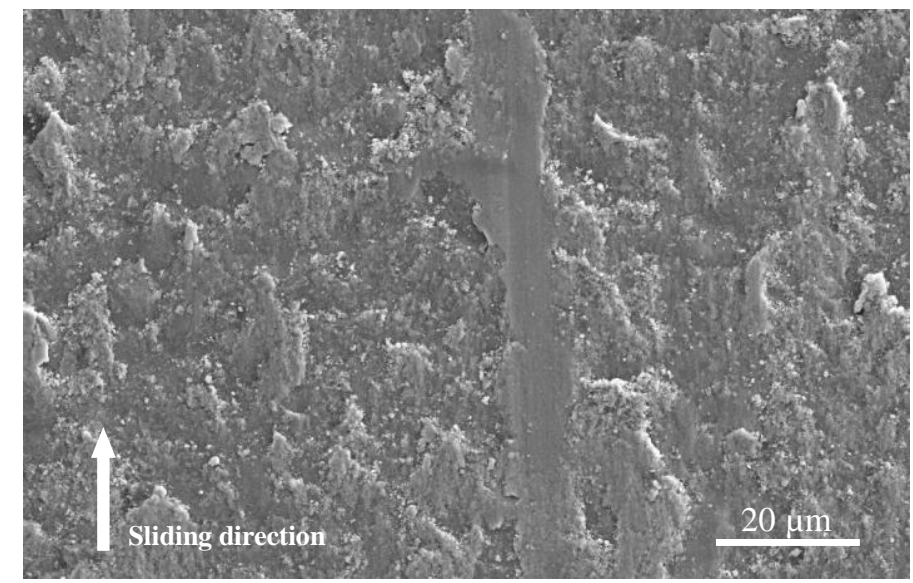

a)

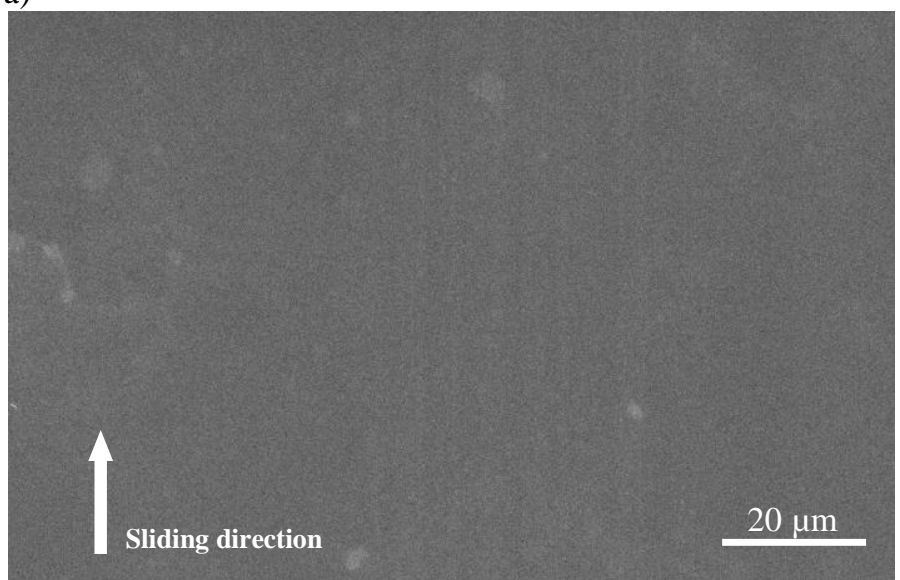

c)

Figure 5. Material pick-up tendency for TiC coated steel disc in sliding contact with the ASTM 52100 pin as observed in the SEM. a) As-deposited coating, dry conditions, b) As-deposited coating, lubricated conditions, c) Post-polished coating, dry conditions. The micrograph in d) shows the absence of wear (i.e. only grinding marks can be seen) of the ASTM 52100 pin when sliding in lubricated contact against post-polished TiC coated Ovatec 677. 


\section{DISCUSSION}

The present results show that it is possible to significantly improve the tribological properties of Ovatec 677 by the deposition of CVD and PVD coatings. However, as discussed by Håkansson [9], in order to avoid material pick-up resulting in high friction coefficients and frictional heating, the asdeposited coatings must be post-treated (microblasted, polished, etc.) in order to reduce the asdeposited surface topography and remove protruding surface irregularities such as droplets/macro particles (PVD coatings) and larger crystals (CVD coatings), small surface cavities/pores being less critical. In the present study this is illustrated by the TiC coating, which displayed a strong correlation between surface roughness and friction coefficient as well as the wear coefficient of the counter surface. The only coating material showing low friction/low material pick-up tendency also in the as-deposited condition is the $\mathrm{CrC} / \mathrm{C}$ coating, which displays intrinsic low friction properties in combination with a relatively low hardness, which can support a running in of a topographic surface.

Of the coatings investigated, the $\mathrm{CrC} / \mathrm{C}$ and $\mathrm{TiC}$ coatings are the two most promising candidates in order to improve the tribological performance of Ovatec 677 steel wire drawing dies. However, since it can be expected that the contact conditions during wire drawing are more severe than those prevailing in the pin-on-disc test, the weak points of the above mentioned coatings must be considered. For the $\mathrm{CrC} / \mathrm{C}$ coating, it can be assumed that the intrinsic wear resistance is the life time limiting factor, i.e. the low shear strength of the coating may result in a too high adhesive wear rate. For the TiC coating the corresponding limiting factor is the low ductility, i.e. the tendency to cracking and chipping when deposited on relatively soft steel substrates (cf. the results obtained in the scratch tests). However, by combining the $\mathrm{CrC} / \mathrm{C}$ coating with a harder subcoating, e.g. $\mathrm{TiC}$, in a dual-layer coating system and thus combining a low friction top-layer with a harder and wear resistant sub-layer, a more robust coating concept can be achieved. This concept may show a high potential in order to reduce friction and wear of steel wire drawing dies. Thus, based on the above results and discussion, three different coatings $-\mathrm{CrC} / \mathrm{C}$, $\mathrm{TiC}$ and dual-layer $\mathrm{TiC} / \mathrm{CrC} / \mathrm{C}$ - are recommended to be evaluated in wire drawing field tests.

\section{CONCLUSIONS}

In the present study the tribological performance of CVD and PVD coated Ovatec 677 aimed for wire drawing applications, has been evaluated by pin-on-disc testing using ASTM 52100 bearing steel as counter material. Coating materials characterised include $\mathrm{TiC}, \mathrm{CrC} / \mathrm{C}, \mathrm{CrN}$ and (Ti,Al)N.

The main conclusions are:

- In order to improve the properties of the asdeposited coatings these should be post-treated by e.g. polishing in order to obtain a smooth surface.

- Polished coatings, as compared with coatings in the as-deposited condition, show not only a lower friction coefficient but also a significantly lower material pick-up tendency indicating less interaction with the steel counter surface.

- The presence of a lubricant - in the present study a sodium stearate soap powder significantly reduces the friction coefficient and the material pick-up tendency.

- Of the coatings investigated the PVD $\mathrm{CrC} / \mathrm{C}$ coating showed the lowest friction coefficient as well as the lowest material pick-up tendency. Also the CVD TiC coating showed excellent performance, but only in the polished condition. 
- The results from the tribological tests show that the $\mathrm{CrC} / \mathrm{C}$ and $\mathrm{TiC}$ coatings prove high potential to significantly improve the tribological performance of Ovatec 677 steel wire drawing dies.

- Based on the above conclusions, three different coatings $-\mathrm{CrC} / \mathrm{C}$, TiC and dual-layer $\mathrm{TiC} / \mathrm{CrC} / \mathrm{C}$ - are recommended to be evaluated in wire drawing field tests.

\section{ACKNOWLEDGMENTS}

The authors greatly acknowledge Henrik Westerlund and Bengt-Olov Stenberg at Ovako Hällefors Processing and Peter Hydén at IonBond Sweden for providing the test materials.

\section{REFERENCES}

1. Gillström, P., Jarl, M., Wear of Die after Drawing of Pickled or Reverse Bent Wire Rod, Wear 262, 2007, pp. 858-867

2. Jacobson, S., Hogmark, S., Tribologi, Friktion, smörjning och nötning (Tribology, Friction, lubrication and Wear, in Swedish), first edition, Liber, Arlöv, 1996

3. Podgornik, B., Hogmark, S., Surface Modification to Improve Friction and Galling Properties of Forming Tools, Journal of Materials Processing Technology 174, 2006, pp. 334-341
4. Miller, T.L., Coating Extends Die Life Improves Finish, Wire Technol. Int. Vol. 17, no. 5, Sept.-Oct. 1989, pp. 46

5. Miura, N. et al, Development of Processing Technologies for Steel Wire Rods and Bars, Nippon Steel Technical Report (Japan), no. 53, Apr. 1992, pp. 57-65

6. Murakawa, M., Takeuchi, S., Yoshida, K., Fabrication of Diamoned-Coated Drawing Die and Basic Performance Test, $2^{\text {nd }}$ International conference on the applications of diamond and related materials, Omiya, Japan, 25-27 Aug. 1993, pp. 589-594.

7. H. J. Van Halewijn, Breakthrough of CVD Diamond in the Applications of Wire Dies, Diamond 1998: $9^{\text {th }}$ European conference on diamond, diamond-like materials, nitrides and silicon carbide, Crete, Greece, 13-18 Sept. 1998

8. Sun, F H. et al, Chemical Vapour Deposition Diamond Coated Drawing Dies, Key engineering materials, Vol. 259-260, 2004, pp. 68-72

9. Håkansson, G., Book of abstracts ICMCTF 2007, p.42, ICMCTF 2007, San Diego, California, USA, April 2007 